Rizvani R. Monitoring the effectiveness of hospital cleaning practices by use of adenosine triphosphate bioluminescence assay. Infect Control Hosp Epidemiol 2009;30:678-684.

7. Lewis T, Griffith C, Gallo M, Weinbren M. A modified ATP benchmark for evaluating the cleaning of some hospital environmental surfaces. J Hosp Infect 2008;69:156-163.

8. Turner DE, Daugherity EK, Altier C, Maurer KJ. Efficacy and limitations of an ATP-based monitoring system. J Am Assoc Lab Anim Sci 2010;49:190-195.

\section{Increasing Influenza Vaccination Rates among Hospital Employees without a Mandatory Policy}

To the Editor-Influenza vaccination is the best way to protect against influenza infection. ${ }^{.}$For healthcare workers, the Centers for Disease Control and Prevention (CDC), the Advisory Committee on Immunization Practices (ACIP), and the Healthcare Infection Control Practices Advisory Committee (HICPAC) all recommend that US healthcare workers get vaccinated annually. During the 2010-2011 influenza season, the influenza vaccination rate among healthcare workers was estimated at $63.5 \%$. However, the rate increased to over $98 \%$ when there was a requirement for vaccination by their employers. ${ }^{1}$ Because of this discrepancy, the Society for Healthcare Epidemiology of America (SHEA) endorsed a policy in which annual influenza vaccination should be "a condition of both initial and continued healthcare personnel employment and/or professional privileges." ${ }^{2}$ Many hospitals have been reluctant to institute such a policy on the basis of both the fear of litigation and the compromising of employees' civil liberties and autonomy. ${ }^{3}$

Virginia Hospital Center (VHC) is a 334-bed teaching hospital in Arlington, Virginia, located in the Washington, DC, metropolitan area. During the 2011-2012 influenza season, there were an estimated 2,723 hospital employees, of which about $20 \%$ had nonclinical roles. Although the hospital administration assured their full support of any influenza vaccination program, they were reluctant to implement a mandatory vaccination policy. We report our experience on trying to improve vaccination rates without instituting an official requirement.

In previous years, $\mathrm{VHC}$ has provided free influenza vaccine; available at different times and locations via mobile carts and centralized dispensing areas. The hospital has also publicized the availability and importance of vaccination at monthly leadership meetings and in the form of posters, e-mail alerts, hospital newsletters, and overhead announcements. Additionally, the use of declination letters has been added to the influenza plan in an effort to increase vaccination rates. Despite these efforts, during the 2010-2011 influenza season, the vaccination rate was $61 \%$, a rate much lower than those achieved in hospitals with mandatory vaccination programs. ${ }^{4,5,6}$

In the months prior to the 2011-2012 influenza season, an influenza task force was created, consisting of members of the Infection Prevention Committee, Employee Health, Medical Staff Office, Pharmacy, Public Affairs, and the hospital administration. A comprehensive vaccination policy was instituted that included methods from previous years as well as 3 additional components: stickers on badges identifying whether individuals were vaccinated or not; use of surgical masks by unvaccinated employees when within 6 feet of a patient; and weekly e-mails to department supervisors updating them on their employees' status. It was required that employees either receive the vaccine or sign a declination letter. Documentation of vaccination outside VHC was acceptable for those vaccinated elsewhere. Additionally, department supervisors had the responsibility to ensure all of their employees took some sort of action. Vaccination started October 1, 2011, and employees were encouraged to take action by December 1, 2011.

During the 2011-2012 influenza season, 2,306 employees received the vaccine or showed proof of vaccination elsewhere, and 141 signed a declination letter, resulting in a $90 \%$ compliance rate with hospital policy. Overall, the vaccination rate was $85 \%$ (Table 1 ). The most common reason for declination was "Personal/Do not want." There was no disciplinary action taken against those who were noncompliant with hospital policy. Vaccination rates were $86 \%$ in clinical employees compared to $74 \%$ in nonclinical employees. One vaccinated employee developed a cough 1 hour after vaccination and was seen in the emergency department. She had no lip or tongue swelling on physical examination and had no wheezing upon auscultation. She was given a short course of steroids for a possible allergic reaction. Nonhospital employees such as students and hospital contractors were provided free vaccine, and vaccination rates were well over $90 \%$ for this population.

We saw a dramatic increase in influenza vaccination rates during the 2011-2012 season, despite not implementing a mandatory vaccination policy. Although we did require some action to be taken, there was no consequence if an employee chose not to do anything or if a supervisor did not enforce the policy. However, because of the aggressive marketing of the vaccine and the requirement to wear a mask if unvaccinated, many

TABLE 1. Influenza Vaccination among Employees over a 5-Year Period

\begin{tabular}{lccc}
\hline Year & $\begin{array}{c}\text { Employees } \\
\text { vaccinated }\end{array}$ & $\begin{array}{c}\text { Total no. of } \\
\text { employees }\end{array}$ & $\begin{array}{c}\text { Vaccination } \\
\text { rate, \% }\end{array}$ \\
\hline 2007 & 932 & 2,053 & 45 \\
2008 & 1,034 & 2,358 & 44 \\
2009 & 1,237 & 2,165 & 57 \\
2010 & 1,363 & 2,239 & 61 \\
2011 & 2,306 & 2,723 & 85 \\
\hline
\end{tabular}


employees assumed that vaccination was mandatory, which helped the compliance rate. Masking has been reported previously as an effective way to increase influenza vaccination among healthcare workers. ${ }^{7}$ In surveys of first-time vaccine recipients, the inconvenience and stigma of masking was the strongest motivator for vaccination. Other factors that influenced vaccination included support of our program from hospital leaders, pressure on employees by their supervisors to take action, effective marketing, and better education regarding the need for vaccination. Problems faced during the year included the lack of enforcement of the influenza policy and some physicians on the medical staff not getting vaccinated, leading to hospital employees doubting the importance of vaccination or the seriousness of influenza.

Although we achieved an $85 \%$ influenza vaccination rate, mandatory vaccination policies have yielded rates of over $98 \%$. Mandatory vaccination is the most effective way to increase rates, yet such policies are still not widely accepted by many hospitals. In institutions where the administration is reluctant to adopt such a policy, we present a model that may be beneficial.

\section{ACKNOWLEDGMENTS}

Potential conflicts of interest. All authors report no conflicts of interest relevant to this article. All authors submitted the ICMJE Form for Disclosure of Potential Conflicts of Interest, and the conflicts that the editors consider relevant to this article are disclosed here.

Rohit M. Modak, MD, MBA; ${ }^{1}$ Sarah M. Parris, RN, MSN, COHN; ${ }^{2}$ Jeffrey P. Dilisi, MD, MBA; ${ }^{3}$ Ajay Premkumar, BS $^{4}$
Affiliations: 1. Department of Medicine, Virginia Hospital Center, Arlington, Virginia; 2. Occupational Health, Virginia Hospital Center, Arlington, Virginia; 3. Administration, Virginia Hospital Center, Arlington, Virginia; 4. Emory University School of Medicine, Atlanta, Georgia.

Address correspondence to Rohit M. Modak, MD, MBA, Division of Infectious Diseases, Virginia Hospital Center, 1715 North George Mason Drive, Suite 108B, Arlington, VA 22205 (rxm2619@virginiahospitalcenter.com). Infect Control Hosp Epidemiol 2012;33(12):1288-1289

(C) 2012 by The Society for Healthcare Epidemiology of America. All rights reserved. 0899-823X/2012/3312-0026\$15.00. DOI: $10.1086 / 667384$

\section{REFERENCES}

1. Influenza Vaccination Information for Health Care Workers. Centers for Disease Control and Prevention website. http://www .cdc.gov/flu/healthcareworkers.htm. Updated November 2011. Accessed April 2011.

2. Talbot TR, Babcock H, Caplan AL, et al. Revised SHEA position paper: influenza vaccination of healthcare personnel. Infect Control Hosp Epidemiol 2010;31(10):987-995.

3. Stewart AM. Mandatory vaccination of healthcare workers. $N$ Engl J Med 2009;361(21):2015-2017.

4. Babcock HM, Gemeinhart N, Jones M, Dunagan WC, Woeltje KF. Mandatory influenza vaccination of healthcare workers: translating policy to practice. Clin Infect Dis 2010;50(4):459-464.

5. Rakita RM, Hagar BA, Crome P, Lammert JK. Mandatory influenza vaccination of healthcare workers: a 5-year study. Infect Control Hosp Epidemiol 2010;31(9):881-888.

6. Karanfil LV, Bahner J, Hovatter J, Thomas WL. Championing patient safety through mandatory influenza vaccination for all healthcare personnel and affiliated physicians. Infect Control Hosp Epidemiol 2011;32(4):375-379.

7. Marx I, Gastelum R. Voluntary employee influenza vaccination with mandatory mask use: a new paradigm. Am J Infect Control 2011;39(5):E75-E76. 